\title{
Studi Keragaman Kelelawar Berdasarkan Perangkap Jaring Kabut di Pusat Latihan Gajah Taman Nasional Way Kambas
}

\section{Study of Bat Diversity Based on Fog Net Traps at the Elephant Training Center in Way Kambas National Park}

\author{
Salih Alimudin ${ }^{1}$, Nuning Nurcahyani ${ }^{1}$, Elizabeth Devi Krismuniarti ${ }^{2}$, Elly L. Rustiati ${ }^{1}$, Eka Sulpin \\ Ariyanti $^{3}$ \\ ${ }^{1}$ Jurusan Biologi, Fakultas Matematika dan IImu Pengetahuan Alam, Universitas Lampung \\ ${ }^{2}$ Taman Nasional Way Kambas (TNWK) \\ 3.Aliansi Lestari Rimba Terpadu (AleRT) Taman Nasional Way Kamnbas \\ "Email: salihalimudin97@gmail.com,ely_jazdzyk@yahoo.com
}

Disubmit: 15 September 2019

Direvisi: 27 Desember 2019

Diterima: 26 Januari 2020

\begin{abstract}
Abstrak: Kelelawar, satu-satunya mamalia terbang, dapat terlihat di Taman Nasional Way Kambas (TNWK), termasuk Pusat Latihan Gajah (PLG). Keberadaan kelelawar dipengaruhi oleh struktur fisik habitat, iklim mikro, ketersediaan air dan sumber makanan, serta interaksi dengan satwa liar lainnya. Di Indonesia terdapat 9 dari 18 kelompok kelelawar dunia, yaitu Pteripodidae, Megadermatidae, Nycteridae, Vespertilionidae, Rhinolopidae, Hipposideridae, Emballonuridae, Rhinopomatidae, Molosidae. Penelitian ini dilakukan dengan menerapkan teknik jaring kabut untuk mempelajari keragaman kelelawar. penangkapan langsung menggunakan mist net dilakukan di 3 titik lokasi, area masjid PLG (lokasi 1), area Rumah Sakit Gajah (lokasi 2), dan area kandang gajah (lokasi 3). Tiga kali ulangan dilakukan selama penangkapan di setiap lokasi. Jumlah kelelawar yang ditangkap $(\mathrm{N}=29)$ terdiri dari 7 spesies, 4 di antaranya adalah kelelawar pemakan buah (Cynopterus minutus, Cynopterus brachyotis, Cynopterus sphinx), Cynopterus titthaecheilus) dan 3 pemakan serangga (Megaderma spasma, Pipistrellus javanicus, dan Scotophilus kuhlili) . Perangkap jaring kabut cocok untuk dilakukan di PLG, TNWK dan keanekaragaman kelelawar representatif diperoleh.
\end{abstract}

Kata kunci: Kelelawar, Keragaman, Pusat Latihan Gajah, Taman Nasional Way Kambas

Abstract: Bats, the only flying mamals, are commonly seen in Way Kambas National Park (WKNP), including Elephant Training Center (ETC). The existence of bats is influenced by physical structures of habitat, microclimate, water availability and food resources, and interaction with other wildlife. In Indonesia there are 9 of the 18 world bat groups, namely Pteripodidae, Megadermatidae, Nycteridae, Vespertilionidae, Rhinolopidae, Hipposideridae, Emballonuridae, Rhinopomatidae, Molosidae. This research was conducted to apply mist net technique to learn the bat diversity. Direct trapping using mist net was conducted in 3 trapping points, ETC mosque area (location 1), Elephant Hospital area (location 2), and elephant resting area (location 3). Three replications were applied during life trapping for each location. The number of bats caught $(N=29)$ consisted of 7 species, 4 of them are fruit-eating bats (Cynopterus minutus, Cynopterus brachyotis, Cynopterus sphinx, Cynopterus titthaecheilus) and 3 insectivores (Megaderma spasma, Pipistrellus javanicus, and Scotophilus kuhlii). Mist net trapping was suitable to be done in ETC, WKNP and representative bat diversity was obtained.

Keywords: Diversity, Bats, Elephant Training Center, Way Kambas National Park 


\section{PENDAHULUAN}

Taman Nasional Way Kambas (TNWK) merupakan salah satu taman nasional tertua di Indonesia dengan beragam jenis fauna di dalamnya. Taman Nasional Way Kambas terletak di Kecamatan Labuhan Ratu Lampung Timur, Kawasan TNWK mempunyai luas $\pm 125,631.31$ ha, secara gaeografi terletak antara $40^{\circ} 37^{\prime}-50^{\circ} 16^{\prime}$ Lintang Selatan dan antara $105^{\circ} 33^{\prime}-105^{\circ} 54^{\prime}$ Bujur Timur. Kawasan konservasi ini ditetapkan sebagai taman nasional pada tahun 1991 berdasarkan Surat Keputusan Menteri Kehutanan Nomor 144/Kpts/ll/1991 tanggal 13 Maret 1991, dan pada tahun 1997 dinyatakan sebagai Balai Taman Nasional Way Kambas (TNWK, 2017).

Kawasan TNWK juga memiliki Pusat Latihan Gajah (PLG) yaitu pusat pelatihan bagi gajah-gajah binaan yang pernah berkonflik dengan manusia maupun gajahgajah yang terpisah dari rombongannya yang didalamnya juga terdapat Rumah Sakit Gajah (RSG) Pertama di Asia Tenggara (Direktorat Jendral Konservasi dan Sumber Daya Alam Kementerian Lingkungan Hidup dan Kehutanan, 2019). Area PLG,TWNK kebanyakan vegetasi lebih terbuka karena didominasi oleh alang-alang. Gajah sumatera (Elephas maximus sumatranus) di PLG, TNWK memiliki kemungkinan berinteraksi baik secara langsung maupun tidak langsung dengan satwa lain termasuk kelelawar. Di PLG kelelawar dan tanda tidak langsung keberadaan kelelawar dapat ditemukan. Kelelawar memiliki banyak peran dalam suksesi hutan karena kelelawar dapat membantu penyebaran biji di hutan dan membantu penyerbukan berbagai jenis tumbuhan buah, bahkan kelelawar pemakan serangga juga berperan dalam mengendalikan populasi serangga. kelelawar juga dapat menularkan berbagai penyakit zoonosis yang dapat ditularkan kepada satwa liar, hewan ternak, bahkan kepada manusia (FAO, 2011). Lokasi yang lebih terbuka karena banyaknya jumlah alang-alang di area PLG,TNWK membutuhkan teknik dan alat yang harus mendukung dalam penangkapan kelelawar, oleh sebab itu dilakukan penelitian ini untuk memilih lokasi, teknik dan alat yang paling efektif dalam penangkapan kelelawar di area ini.

\section{METODE PENELITIAN}

\section{Waktu dan Lokasi Penelitian}

Penelitian ini dilakukan pada Februari-Maret 2019 di Pusat Latihan Gajah, Taman Nasional Way Kambas, Kecamatan Labuhan Ratu, Kabupaten Lampung Timur.

\section{Alat dan Bahan}

Alat yang digunakan pada kegiatan penelitian ini adalah Global Positioning System (GPS) Garmin 72h untuk menentukan titik lokasi, Mist net sebagai perangkap kelelawar, kaliper untuk mengukur morfometri kelelawar, timbangan pesola untuk mengukur berat kelelawar, kantung belacu untuk meletakkan kelelawar yang telah ditangkap, buku identifikasi Panduan Lapangan Kelelawar di Indonesia Suyanto (2001), Bats of Krau Wildlife Reserve Kingston, Lim dan Zubaid (2006), Kelelawar Sulawesi Jenis Peranannya dalam kesehatan (Yuliadi, Tika dan Farida, 2014). Identifikasi kelelawar juga dibantu dengan kamera handphone Asus tipe Z010D, tagging/ wing punching untuk menandai kelelawar yang sudah pernah diidentifikasi. 


\section{Survei Pendahuluan}

Survei pendahuluan merupakan kegiatan pemilihan lokasi yang tepat untuk menentukan titik penangkapan kelelawar dengan melihat tanda tidak langsung maupun adanya keberadaan kelelawar secara langsung. Pada survei pendahuluan ditemukan tanda keberadaan kelelawar mulai dari bekas buah sisa pakan kelelawar, bekas kotoran dan adanya individu/kelompok kelelawar di PLG, TNWK. Berdasarkan survei yang telah dilakukan, maka dipilih 3 lokasi yang menjadi titik penangkapan kelelawar.

\section{Koleksi Data}

Koleksi data merupakan kegiatan pengambilan data dengan melakukan penangkapan kelelawar pada waktu aktif kelelawar yaitu 18.00-22.00 WIB di PLG, TNWK dengan pengecekan setiap 15 menit pada lokasi yang sudah ditentukan (Kunz, 1988). Pengambilan data dilakukan di 3 titik lokasi dengan masing-masing titik lokasi dilakukan penangkapan selama 3 malam. Masing-masing titik pengambilan data yaitu:

\section{Lokasi 1 (belakang kantin Sekitar Mushola PLG, TNWK)}

Pemasangan perangkap mist net /jaring kabut di lokasi 1 pada koordinat $48 \mathrm{M}$ 0582021 UTM 9433941 yaitu di sekitar belakang kantin dekat mushola PLG (Gambar 1).

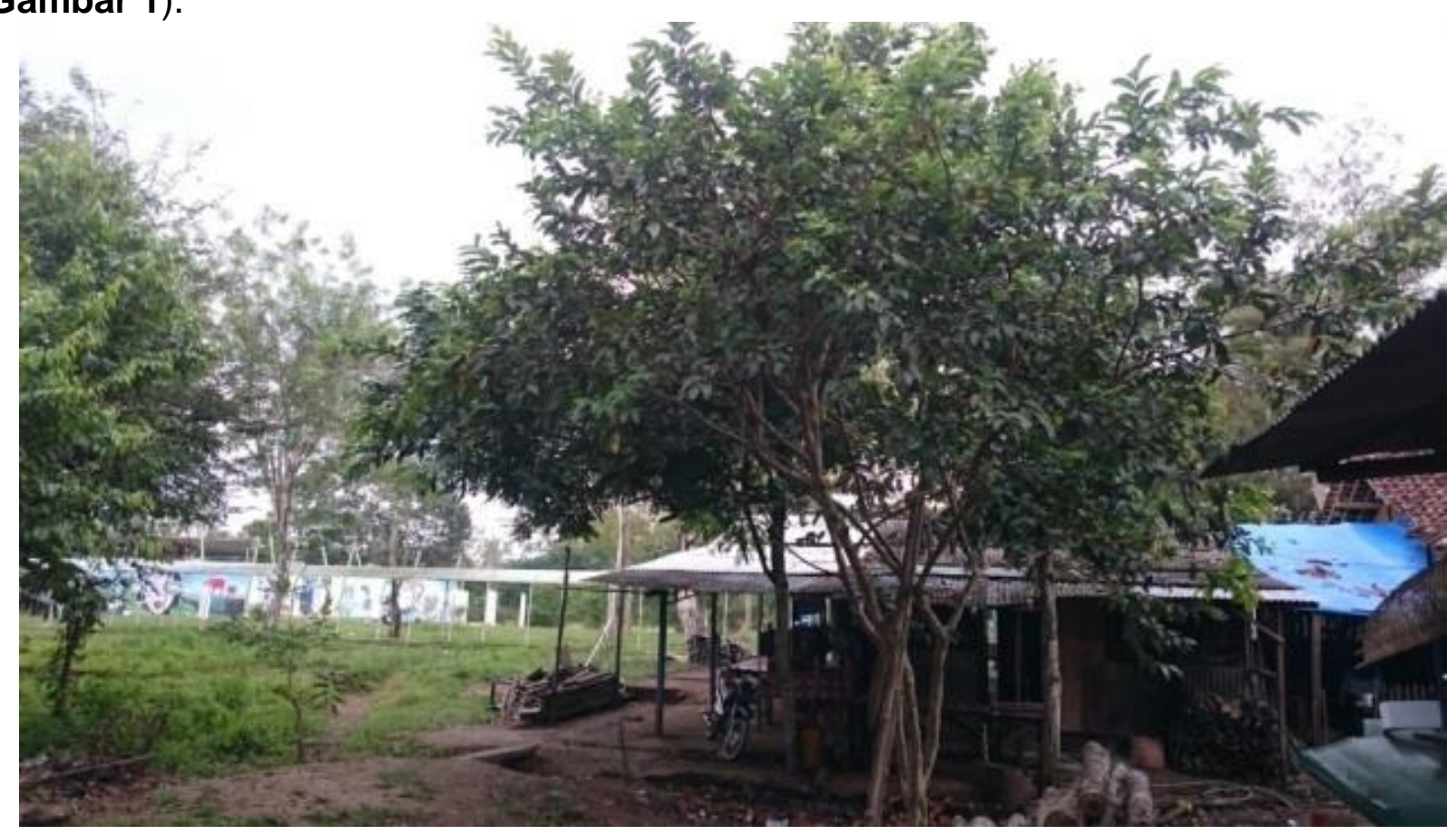

Gambar 1. Lokasi belakang kantin sekitar mushola PLG, TNWK

pemasangan di titik tersebut dilakukan karena melihat adanya pakan kelelawar pemakan buah yaitu jambu biji (Psidium guajava).

\section{Lokasi 2 (Area Sekitar Rumah Sakit Gajah)}

Pemasangan perangkap mist net/jaring kabut lokasi pada koordinat $48 \mathrm{M}$ 0582408 UTM 9433941 di sekitar Rumah Sakit Gajah (Gambar 2). 


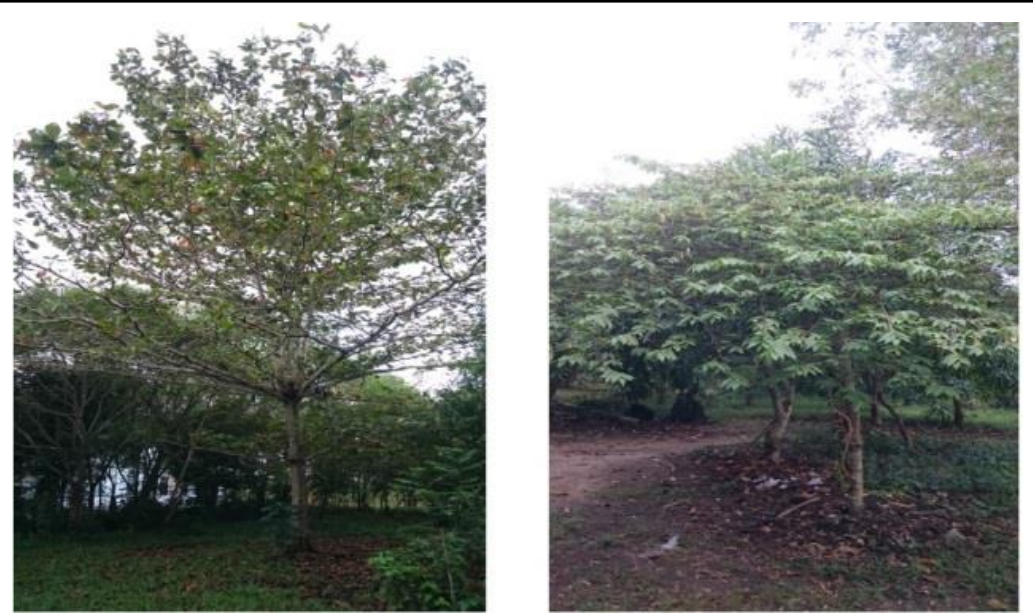

Gambar 2. Lokasi sekitar Rumah Sakit Gajah, TNWK

pemasangan di titik tersebut dilakukan karena di lokasi tersebut terdapat jenis buah pakan kelelawar ( $\mathrm{A}=$ Terminalia catappa) dan ( $\mathrm{B}=$ Muntingia sp.).

Lokasi 3 (Area sekitar lampu penerangan di Kandang gajah besar)

Pemasangan perangkap mist net/jaring kabut lokasi pada koordinat $48 \mathrm{M}$ 0582177 UTM 9433665 (Gambar 3)

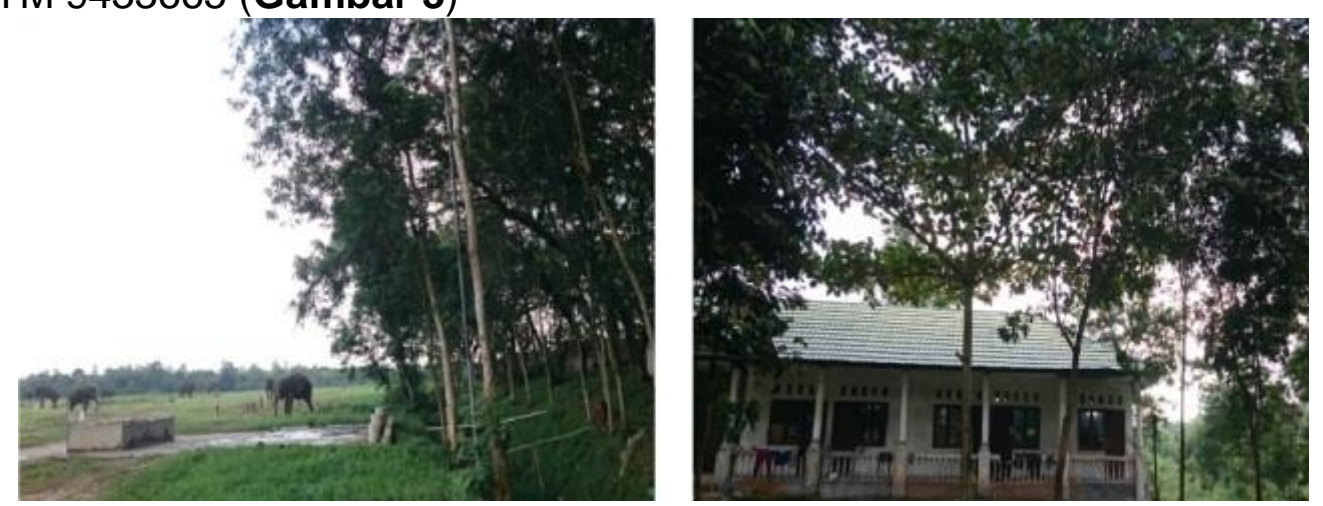

Gambar 3. Lokasi sekitar lampu penerangan di kandang gajah

Pemasangan di titik tersebut dilakukan karena di dalam kandang gajah besar terdapat lampu penerangan, di sekitar lampu penerangan terdapat banyak serangga yang merupakan pakan alami kelelawar pemakan serangga. Pada lokasi ketiga ulangan ke 3 dilakukan pergeseran titik pemasangan jaring kabut untuk memaksimalkan keragaman kelelawar yaitu di area rumah mahut dekat kandang karantina.

Koleksi data dilakukan dengan pemasangan jaring kabut/mist net dengan pengecekan setiap 15 menit sekali. Kelelawar yang sudah ditangkap akan diidentifikiasi, proses identifikasi dilakukan dengan melakukan pengukuran morfometri kelelawar dan mendokumentasikan menggunakan kamera handphone merk Asus tipe Z010D.

Kelelawar yang telah ditangkap diidentifikasi dengan merujuk pada buku Panduan Lapangan Kelelawar di Indonesia Suyanto (2001), Bats of Krau Wildlife Reserve Kingston, Lim dan Zubaid (2006) Kelelawar Sulawesi Jenis Peranannya dalam kesehatan (Yuliadi, Tika dan Farida, 2014).

\section{Parameter}

Parameter yang diamati pada penelitian ini yaitu morfometri, jenis kelamin, status reproduksi kelelawar dan umur kelelawar. 


\section{Jenis Kelamin dan Status Reproduksi}

Jenis kelamin pada kelelawar jantan dapat dilihat dengan ada tidaknya penis, sedangkan pada kelelawar betina dapat dilihat dengan ada tidaknya puting susu.

Status reproduksi kelelawar betina terbagi menjadi 5 kategori yaitu: (1) non reproduktif (NR) adalah kondisi betina yang belum bereproduksi, (2) pregnant $(\mathrm{P})$ yaitu individu betina dalam kondisi hamil, (3) lactating (L) yaitu individu betina dalam kondisi menyusui, (4) recent post lactating (RPL) yaitu kondisi individu betina baru berhenti menyusui sedangkan (5) post lactating (PL) adalah kondisi betina yang sudah pernah menyusui (Howell dan Roth, 1981).

Berbeda dengan status reproduksi betina, status reproduksi kelelawar jantan dapat dilihat dengan melihat ukuran skrotum: (1) testes swollen yaitu testis pada kelelawar mengalami pembengkakan, (2) testes slightly swollen yaitu testis pada kelelawar mengalami sedikit pembengkakan, (3) testes not swollen yaitu testis pada kelelawar tidak mengalami pembengkakan (Howell dan Roth, 1981).

\section{Umur Kelelawar}

Umur kelelawar terbagi menjadi 3 yaitu bayi (pup) $(\mathrm{P})$, anakan (juvenile) (J) dan dewasa (adult) (A) Kingston, Lim dan Zubaid (2006) Umur kelelawar dapat diketahui dengan melihat dengan menyorot bagian metakarpal dan phalanx menggunakan lampu senter. Kelelawar pada keadaaan pup (bayi) biasanya masih menempel dengan induknya dan metacarpal dan phalanx masih bersambung pada tulang kartilagonya. Ketika juvenile $(\mathrm{J})$ persambungan tulang metakarpal dan phalanx sudah menyatu, sedangkan pada kondisi adult (A) persambungan antara keduanya terdapat bentuk seperti pita (Burnett and Kunz. 1982) (Gambar 4).

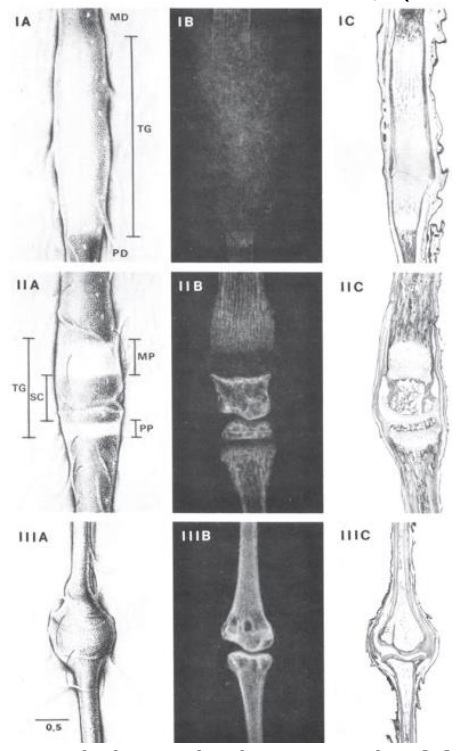

Gambar 4. Persambungan metakarpal dan phalanx pada Myotis lucifugus Atas = pup (P); tengah $=$ juvenile $(\mathrm{J})$; bawah=adult $(\mathrm{A})$ [(Burnett and Kunz. 1982).

\section{Pengukuran Morfometri Kelelawar}

Kelelawar yang tertangkap di masukkan ke dalam kantung belacu. Kelelawar diukur secara morfometri sebelum kelelawar tersebut dilepaskan kembali di lokasi kelelawar tertangkap. Pengukuran morfometrik pada kelelawar meliputi tinggi telinga $(E L)$, panjang ekor (T), panjang lengan bawah/forearm (FA), panjang betis/tibia (TB), panjang badan dan kepala (HB), dan panjang tulang kaki (HF) . 
Morfometri kelelawar diukur menggunakan kaliper. Panjang lengan bawah/forearm (FA) diukur dari sisi luar siku sampai sisi luar pergelangan tangan pada sayap yang melengkung. Panjang betis/tibia (TB) diukur dari sendi lutut hingga sendi pergelangan kaki. Panjang telinga/ear diukur dari pangkal telinga hingga ujung telinga. Panjang ekor diukur dari pangkal ekor sampai ujung ekor dan tidak termasuk rambut yang memanjang melebihi ekor. Panjang HB diukur ujung moncong sampai bagian tubuh sebelum pangkal ekor. Panjang kaki belakang/hindfeet diukur dari ujung tumit ke ujung digit terpanjang cakar. Berat kelelawar dihitung dengan menimbang stocking, kemudian memasukkan kelelawar kedalam stocking dan mengurangi berat total kelelawar dan stocking dengan berat stocking menggunakan timbangan pesola (Huang et al.2014).

\section{Analisis Data}

Data hasil penelitian dianalisis secara deskriptif.

\section{HASIL DAN PEMBAHASAN}

Penangkapan dilakukan menggunakan mistnet di 3 lokasi dengan masingmasing Kandang gajah besar kali penangkapan telah dilaksanakan pada Februari-Maret 2019 di PLG, TNWK dan diperoleh 29 individu (N) yang terdiri dari 7 jenis kelelawar yaitu Cynopterus minutus $(n=3)$, Cynopterus brachyotis $(n=9)$, Cynopterus sphinx $(n=1)$, Cynopterus titthaecheilus $(n=4)$, Pipistrellus javanicus $(n=2)$ Scotophillus kuhlii $(n=4)$ dan Megaderma spasma $(n=2)$ (Tabel 1).

Tabel 1. Jenis Kelelawar di Pusat Latihan Gajah, Taman Nasional Way Kambas $(\mathrm{N}=29)$

\begin{tabular}{|c|c|c|c|c|}
\hline No & Nama Lokal & Nama Ilmiah & $\begin{array}{l}\text { Jumlah Individu } \\
\text { (n) }\end{array}$ & Suku \\
\hline 1 & Codot mini & Cynopterus minutus & 3 & Pteripodidae \\
\hline 2 & Codot kerawar & $\begin{array}{l}\text { Cynopterus } \\
\text { brachyotis }\end{array}$ & 9 & Pteripodidae \\
\hline 3 & Codot barong & Cynopterus sphinx & 1 & Pteripodidae \\
\hline 4 & Codot besar & $\begin{array}{c}\text { Cynopterus } \\
\text { tithaecheilus }\end{array}$ & 8 & Pteripodidae \\
\hline $\begin{array}{l}5 \\
6\end{array}$ & $\begin{array}{l}\text { Nighi jawa } \\
\text { Pedan asia }\end{array}$ & $\begin{array}{l}\text { Pipistrelus javanicus } \\
\text { Scotophilus kuhlii }\end{array}$ & $\begin{array}{l}2 \\
4\end{array}$ & $\begin{array}{l}\text { Vespertilionidae } \\
\text { Vespertilionidae }\end{array}$ \\
\hline 7 & Vampir palsu & Megaderma spasma & 2 & $\begin{array}{c}\text { Megadermatida } \\
\mathrm{e}\end{array}$ \\
\hline \multicolumn{3}{|c|}{ Total $(\mathbf{N})$} & 29 & \\
\hline
\end{tabular}

Kelelawar yang tertangkap di Pusat latihan Gajah, Taman Nasional Way Kambas terdapat 2 kelompok berdasarkan pakannya yaitu pemakan buah dan pemakan serangga. Kelelawar pemakan buah yang ditemukan hanya terdiri dari 1 genus dan 4 jenis di dalamnya, sedangkan kelelawar pemakan buah yang ditemukan berasal dari 2 suku yaitu Vespertilionidae dengan 2 jenis yaitu Scotophilus kuhlii dan Pipistrellus javanicus serta suku Megadermatidae dengan 1 jenis yang ditemukan yaitu Megaderma spasma.

Setiap lokasi penangkapan memiliki jenis dan jumlah individu kelelawar yang berbeda (Gambar 5) 


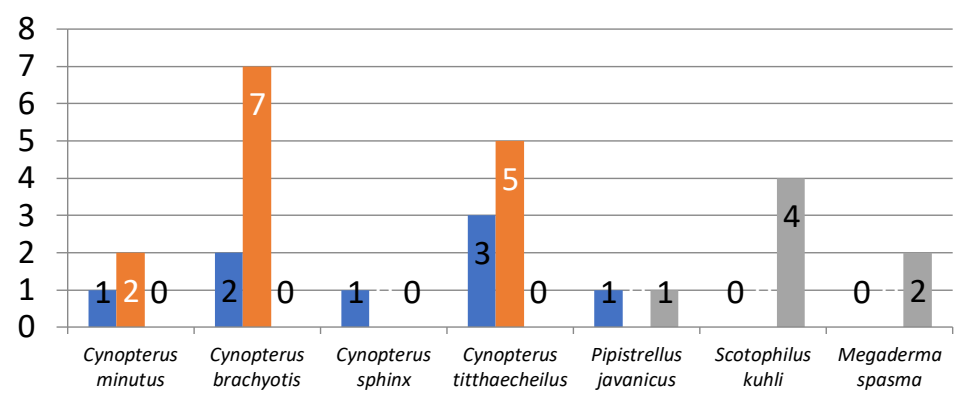

\author{
- Belakang Mushola PLG, TNWK $\quad$ Area RSG, TNWK \\ Kandang Gajah Besar
}

Gambar 5. Jumlah individu jenis-jenis kelelawar ditemukan di Pusat Latihan Gajah, Taman Nasional Way Kambas

Data di atas memperlihatkan bahwa kelelawar pemakan buah hanya ditemukan di Belakang Mushola PLG, TNWK dan 2 sedangkan kelelawar pemakan serangga ditemukan di Belakang Mushola PLG, TNWK dan Kandang gajah besar dan paling banyak ditemukan di Kandang gajah besar. Lokasi pengambilan data tentu memengaruhi jenis kelelawar yang ditangkap. Di Belakang Mushola PLG, TNWK terdapt pohon jambu biji (Psidium guajava) dan di Area RSG, TNWK terdapat pohon ketapang (Terminalia catappa), keduanya merupakan pakan kelelawar sehingga memungkinkan kelelawar melewati lokasi tersebut untuk mencari makan pada jam aktif kelelawar. Kelelawar pemakan serangga hanya ditemukan 1 individu di Belakang Mushola PLG, TNWK yaitu jenis Pipistrellus javanicus dan individu serta jenis lainnya hanya ditemukan di Kandang gajah besar. Lokasi ke 3 merupakan lokasi Kandang Gajah Besar, di dalam kandang gajah terdapat lampu penerangan dan pemasangan mist net tepat di sekitar lampu penerangan tersebut, hal ini berbanding lurus dengan jenis kelelawar yang ditangkap karena di sekitar lampu banyak serangga berterbangan sehingga banyak kelelawar yang melalui jalur ini untuk mencari makan berupa serangga.

\title{
SIMPULAN
}

Penggunaan mistnet/jaring kabut efektif digunakan untuk menangkap kelelawar di area terbuka. Penentuan titik lokasi berbanding lurus dengan jenis kelelawar yang tertangkap. Kelelawar pemakan buah terdapat di lokasi penangkapan yang terdapat jenis buah pakan kelelawar dan jenis pemakan serangga banyak terdapat di area kandang gajah besar karena terdapat banyak serangga di daerah tersebut sebagai pakan alami kelelawar pemakan serangga.

\section{DAFTAR PUSTAKA}

Burnett, C. D., and T. H. Kunz. 1982. Growth rates and age estimation in Eptesicus fuscus and comparison with Myotis lucifugus. Journal of Mammalogy 63: 33-41. 
Direktorat Jendral Konservasi dan Sumber Daya Alam Kementerian Lingkungan Hidup dan Kehutanan. ksdae.menlhk.go.id/berita/925/rs-gajah-pertama-di-asiatenggara-dikunjungi-dirjen-ksdae.html, diakses pada 15 Januari 2019.

FAO. 2011. Investigating the role of bats in emerging zoonoses: Balancing ecology, conservation and public health interest.

Howell, DJ dan Roth, BS. 1981. Sexual reproduction in agaves: The benefits of bats; the cost of semelparous adverstising Ecology 62(1): 1-7.

Huang, C.C., Elly L.R., Mayner, N., Maryanto, I., Maharadatunkamsi., Sigit, W., Tigga, K. 2014. A Recent Bat Survey Reveals Bukit Barisan Selatan Lanscape as a Chiropteran Diversity Hotspot in Sumatra. Acta Chiropterologica 16(2): 413449. Museum and institute of Zoology, Polish Academy of Science.

Kingston T, BL Lim dan A Zubaid. 2006. Bats of Krau Wildlife Reserve. Universiti Kebangsaan Malaysia. Malaysia.

Kunz, T.H. 1988. Ecological and Behavioral Methods for The Study of Bats. Washington: Smithsonian Insttitution Press.

Suyanto, A. 2001. Seri Panduan Lapangan Kelelawar di Indonesia. Bogor: Puslitbang - LIPI. Bogor.

TNWK. 2017. http://waykambas.org/. Diakses pada 14 November 2018 Pukul 08.00 WIB.

Yuliadi, B., Tika, F.S., Farida, D.H. 2014. Kelelawar Sulawesi Jenis dan Peranannya dalam Kesehatan. Badan Penelitian dan Pengembangan Kesehatan Kementerian Kesehatan RI. 